\title{
PROCESS PARAMETER INFLUENCE ON TENSILE PROPERTY OF FRICTION STIR PROCESSED AI/Ni-Fe COMPOSITE
}

\author{
L. Magondo ${ }^{1}$, M. B. Shongwe ${ }^{1}$, R. M. Mahamood $2,3^{*}$, \\ S. A. Akinlabi4, S. Hassan', H. Dong ${ }^{5}$, K. F. Carter 6 , \\ E. T. Akinlabi² \\ ${ }^{1}$ Institute for Nanoengineering Research, Department of Chemical, Metallurgical \& Materials Engineering, \\ Tshwane University of Technology, P.M.B. X680, Pretoria, South Africa \\ ${ }^{2}$ Department of Mechanical Engineering science, University of Johannesburg, P O Box 524, Auckland park \\ 2006, South Africa \\ ${ }^{3}$ Department of Materials and Metallurgical Engineering, University of Ilorin, Nigeria \\ ${ }^{4}$ Department of Mechanical Engineering, Butterworth Campus, Walter Sisulu University \\ ${ }^{5}$ Materials Innovation Centre, School of Engineering, University of Leicester, United Kingdom \\ ${ }^{6}$ Engineering Department University of Leicester, United Kingdom \\ *Corresponding author's e-mail address: mahamoodmr2009@gmail.com
}

\begin{abstract}
Friction stir processing (FSP) is a solid-state processing technique that has proven to be an efficient surface modification process for producing aluminium matrix composites (AMCs). However, practical challenges still occur during the processing of AMCs even though extensive progress has been made in recent years. In the present study, the influence of FSP process parameters on the tensile property of Al$\mathrm{Ni}-\mathrm{Fe}$ composite has been investigated. The process parameters studied were rotational speed and advancing speed. The rotational speed varied between 600 and $1000 \mathrm{rpm}$ while the advancing speed varied between 70 and $210 \mathrm{~mm} / \mathrm{min}$. The rotational speed was kept constant at each setting and the advancing speed varied. Other processing parameters were kept constant throughout the experiments. The results were compared with those of the base metal (Al). The results showed that the tensile strength decreased as the advancing speed increased. The highest tensile strength was obtained at a rotational speed of $1000 \mathrm{rpm}$ and an advancing speed of $70 \mathrm{~mm} / \mathrm{min}$.
\end{abstract}

KEYWORDS: Advancing speed, Aluminium alloy composite, Friction Stir Processing, rotational speed, tensile strength.

\section{INTRODUCTION}

Aluminium and its alloys possess desirable properties such as high corrosion resistance and light weight, thus making them a favourite for a variety of applications such as household foil, automotive and aerospace parts [1], The light weight is one of the important characteristics of Aluminium that makes the automotive and aerospace industries be in high demand of this material. The reason why this is not far-fetched is its ability to help reduce the carbon footprint of these industries [2].

In spite of the interesting properties of Aluminium and its alloys, they cannot perform up to expectations in some applications where better surface is required. This can be improved by modifying the surface properties of aluminium and its alloys by introducing a reinforcing material to produce a hybrid composite with the desired properties [3]. Having a composite metal matrix on the surface improves the surface properties in respects such as better resistance to wear, improved hardness, and to some extent high temperature stability at the surface [4], [5]. It is used in a wide range of applications when the surface needs to possess excellent mechanical properties, like improved strength and better hardness. The selection criteria for reinforcing materials are dependent on the area and mode of application. In applications where high temperature resistance is required, high temperature materials such as Nickel are used as reinforcement material. Metal matrix composites (MMCs) for example with Aluminium matrix exhibit improved properties, as well as a combination of properties that cannot be obtained from the individual materials making up the composite, which include: lightweight, high strength, stiffness, better wear 
resistance, creep resistance, electrical and high thermal resistance [6], making them highly demanded in the aeronautics, automotive, nuclear energy industries, etc. [7]. The reinforcement materials for the fabrication of hybrid surface composites were chosen based on the properties they possess, in this case nickel which possesses good corrosion resistance, and iron, which possesses bulk density. Nickel and Iron powders were selected taking into consideration what they collectively offer as reinforcing phases into the bulk matrix (Al). Processing aluminium through fusion based technology poses several challenges and is subject to unwanted chemical reactions that are detrimental to the property of the final composite produced. The fusion-based system processing of Aluminium is characterized by defects such as distortions, gas inclusion, tunnel defects, porosity, etc [8]. Therefore, the need for a better and a solid-state processing of Aluminium and its alloys arises.

Friction Stir Processing (FSP) is a solid-state material surface processing technique, an advanced manufacturing technology that has been used to produce hybrid composites with improved properties [9]. FSP uses a non-consumable cylindrical shouldered tool with a pin at the end, which is rotated at a predetermined speed (rpm), plunged into a material surface, and stirs the surface of the bulk material and the reinforcing material, thereby creating a synergy of friction and heat that softens the material, resulting in a uniform mixing and refinement of grain structures [8]-[11]. FSP has drawn considerable attention in the research community due to the excellent microstructural and mechanical property improvements, such as grain refinement, high tensile strength, and better fatigue strength [12]. Fine microstructures with equiaxed recrystallized grains improve the superplasticity performance of material manufacture, and this has been shown to happen for aluminium alloys [13].

In this study, the effect of the Friction Stir Processing parameters on the tensile property of the friction stirred processed surface of the (FSPed) Al$\mathrm{Ni}-\mathrm{Fe}$ composite was analysed. Nickel and iron were introduced as reinforcing material on the surface of the aluminium matrix to generate surface composites (Aluminium matrix composites (AMCs)) with properties dissimilar from the bulk material (Al).

\section{MATERIALS AND EXPERIMENTAL PROCEDURE}

The base metal that was used in this study is a commercially available pure aluminium alloy sheet with a thickness of $5 \mathrm{~mm}$. Nickel powder that contains $99.9 \% \mathrm{Ni}$, with an average particle size of 44 $\mu \mathrm{m}$, in combination with Iron powder of $99.9 \% \mathrm{Fe}$ and between 2.2-3.0 $\mu \mathrm{m}$ particle size range were used as reinforcement powder, supplied by Wear Tech (PTY) limited, South Africa. Shaker Mixer
TURBULA Type T2 C was employed to mix the Asreceived feedstock powders of Nickel and Iron. The TURBULA mixer is a machine used to homogeneously mix powders with different specific weights and particle sizes. The FSP experiment was conducted by placing the $\mathrm{Ni}-\mathrm{Fe}$ reinforcing particles in a groove created on the Al sheet, $3 \mathrm{~mm}$ by $3 \mathrm{~mm}$ in size, placed in the middle of the metal sheet. The rotation tool was plunged into the groove and stirred the matrix and the reinforcing powder uniformly as shown in the schematic diagram of the FSP shown in figure 1. As the tool is plunged into the workpiece and rotates, the materials that are all in a solid state start to turn into a semi solid state material from the Advancing side (AS), and move around the tool pin which is then retreated and cooled in the retreating side (RS). The specimens were subjected to one pass with the same rotational direction using the process parameters shown in table 1 . The tool's tilt angle was maintained at $3^{\circ}$ from the vertical axis throughout the experiments. The FSP tool was made of $\mathrm{H} 13$ hardened steel, $20 \mathrm{~mm}$ in shoulder diameter, and a cylindrical pin of $4 \mathrm{~mm}$ in diameter.

After the FSP experiments were completed, samples for tensile tests specimens were cut into a dumbbell shape using wire Electrical discharge machining (EDM). The dimension of the sample was programmed into the EDM machine and the samples were cut automatically. The dimension of the tensile test specimens used was in accordance with AASHTO: T68 standard as shown in figure 2. The tensile test specimens were machined from both the parent material and the FSPed samples so that to allow the comparison of the results. Three tensile test specimens were machined from each FSPed samples and from the base metal- aluminium.

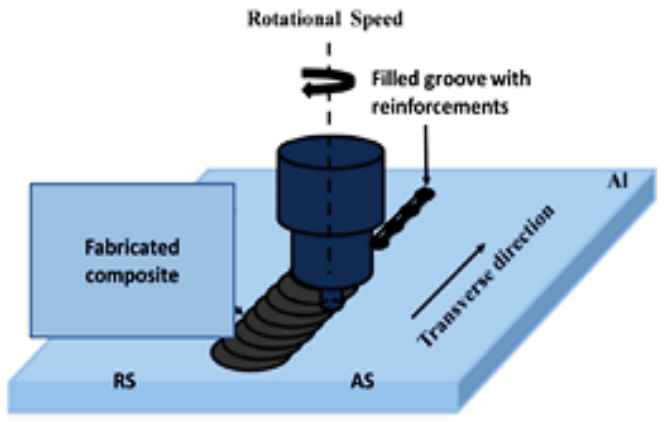

Fig. 1. Scheme of the FSP procedure for $\mathrm{Al} / \mathrm{Ni}-\mathrm{Fe}$ composites production

Table 1. Experimental matrix

\begin{tabular}{|cc|}
\hline $\begin{array}{c}\text { Rotational speed } \\
{[\mathbf{r p m}]}\end{array}$ & $\begin{array}{c}\text { Advancing speed } \\
{[\mathbf{m m} / \mathbf{m i n}]}\end{array}$ \\
\hline 600 & $70 ; 140,210$ \\
800 & $70 ; 140 ; 210$ \\
1000 & $70 ; 140 ; 210$ \\
\hline
\end{tabular}




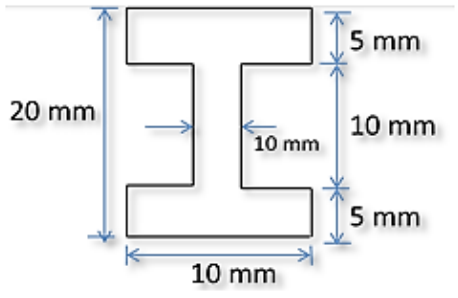

Fig. 2. Dumbbell specimen dimension

The tensile test was performed using a computerized tensile tester INSTRON 1195 by clamping the test specimen from the shoulders and pulling it apart by exerting a load (N) until the specimen reaches the fracture point. The cross-head speed was set at $2 \mathrm{~mm} / \mathrm{min}$ and the extension was obtained using Digital image correlation (DIC). The load versus extension curves of the FSPed samples were produced to compare the tensile behaviour of pure aluminium with the FSPed AMCs samples. The fractured surfaces were also studied. After the tensile tests, the fracture surfaces of the failed samples were studied using Japan Electron Optics Laboratory (JEOL) scanning electron microscope (SEM) JEOL $7600 \mathrm{~F}$ equipped with Energy-Dispersive Spectroscopy (EDS). The magnification of the SEM is in the range of $20 \mathrm{X}$ to approximately $30000 \mathrm{X}$ with spatial resolution of 50 to $100 \mathrm{~nm}$.

\section{RESULTS AND DISCUSSIONS}

The graphs of the load against extension of the tensile test FSPed sample produced at a rotational speed of $600 \mathrm{rpm}, 800 \mathrm{rpm}$ and $1000 \mathrm{rpm}$ as compared to those of the commercially pure aluminium sample are shown in figure 3,4 , and 5, respectively. We drew bar charts of the tensile tests results of commercially pure aluminium and FSPed samples produced at a rotational speed of 600,800 and $1000 \mathrm{rpm}$.

In figure 3, it can be seen that the FSPed AMCs samples produced at a rotational speed of 600rpm with the varying advancing speeds of 70,140 , and $210 \mathrm{~mm} / \mathrm{min}$ all have improved tensile properties when compared to the base metal. It took approximately another $1.5 \mathrm{~mm}$ for the AMCs to reach the breaking point as compared to the pure aluminium. This suggests that the elongation feature improved. With a low rotational speed such as 600rpm, inadequate heat input hinders the material's plasticization, thus limiting the adequate mixing of reinforcement material with the bulk matrix material. From figure 4, it can be observed by looking at the transition of the projections as compared to what was observed in figure 3 that the increase in the rotational speed provides better heat input. Enough heat is imparted into the material, which promotes severe plastic deformation, resulting in the homogeneous distribution of reinforcement into the aluminium matrix. The UTS values of the AMCs in comparison with pure aluminium decreased more, as well as the elongation, which supports that there is a transition from ductile to brittle mechanism. According to Sai Sashank et al, [14] high rotational speed leads to a decline in the UTS value. This is because higher speeds are susceptible to the occurrence of a lack of bonding.

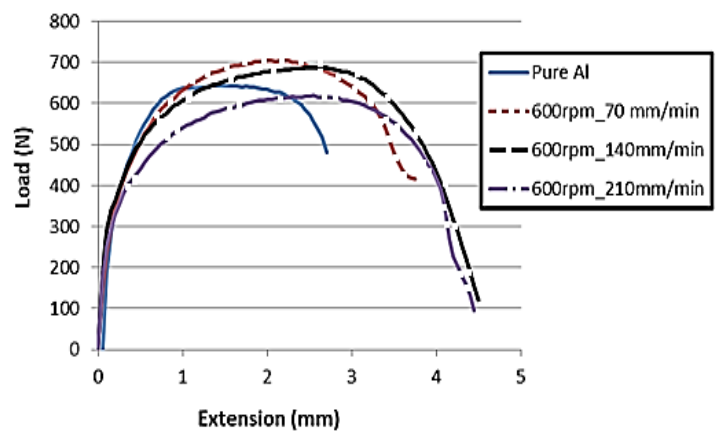

Fig. 3. The graphs of load versus extension of tensile test sample of Pure Al and FSPed samples produced

at rotational speed of $600 \mathrm{rpm}$ and at advancing speeds of $70 \mathrm{~mm} / \mathrm{min}, 140 \mathrm{~mm} / \mathrm{min}$ and $210 \mathrm{~mm} / \mathrm{min}$

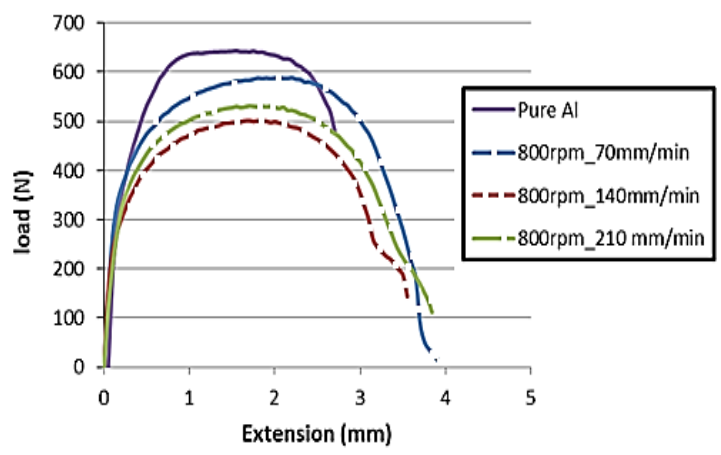

Fig. 4. The graphs of load versus extension of tensile test samples of Pure Al and FSPed samples produced at rotational speed of $800 \mathrm{rpm}$ and at advancing speeds of $70 \mathrm{~mm} / \mathrm{min}, 140 \mathrm{~mm} / \mathrm{min}$ and $210 \mathrm{~mm} / \mathrm{min}$

Also, it is possible for the composite to have tunnel defects resulting from the improper mixing of the reinforcing phase with the matrix particles. In figure 5 , the ultimate strength decreased with the increase of the advancing speed. Although, higher rotational speed produces adequate heat input to properly plasticize the material, and the low advancing speed provides enough time for diffusion to occur, resulting in the homogeneous distribution of reinforcements and the bonding of the reinforcement materials into the matrix of the base material.

This result is consistent with that obtained by Eskandari et al, [15] and Akinlabi et al [16] who showed that an increase in rotational speed, and a decrease in advancing speed results in more uniform precipitation of particles into the aluminium matrix. 


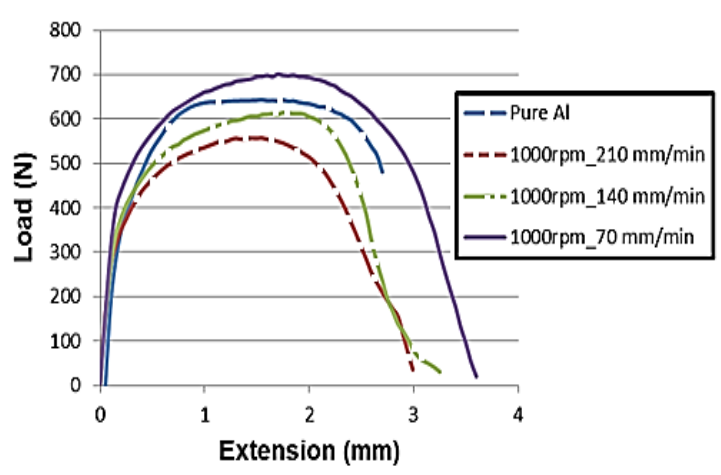

Fig. 5. The graphs of load versus extension of tensile test sample of Pure Al and FSPed samples produced at rotational speed of $1000 \mathrm{rpm}$ and advancing speeds of $70 \mathrm{~mm} / \mathrm{min}, 140 \mathrm{~mm} / \mathrm{min}$ and $210 \mathrm{~mm} / \mathrm{min}$

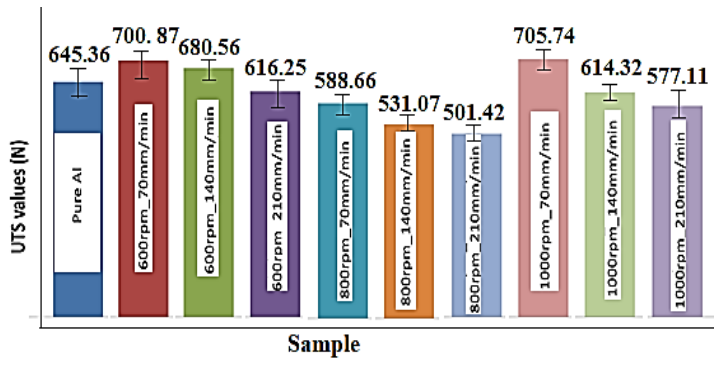

Fig. 6. UTS for pure Al in comparison with AMCs

It can be seen from figure 6 that the FSPed sample produced at a rotational speed of $1000 \mathrm{rpm}$ and an advancing speed of $70 \mathrm{~mm} / \mathrm{min}$ produces the highest tensile strength. This can be attributed to the even distribution of the reinforcement particles achieved at such high rotational speed and low advancing speed, that provides adequate time for the proper mixing of the matrix and the reinforcement. The fractography of the fractured samples are discussed in the next section.

\section{FRACTROGRAPHY}

The SEM micrograph of the fractured surface of the base metal is shown in figure 7 . The morphology of the fracture surface of the commercially pure aluminium in figure 7 shows that the fracture mode is ductile, characterized by the nucleation of microvoids, followed by stable crack growth until coalescence (the process by which two or more droplets, bubbles or particles merge during contact to form a single daughter droplet, bubble or particle) of neighbouring voids. The accumulation of void linkage leads to the formation of a macroscopic crack that finally propagates until final rupture, producing the characteristic deep large dimples.

The fracture surfaces of the FSPed sample produced at a constant rotational speed of $600 \mathrm{rpm}$ and varying advancing speed of 70, 140 and 210 $\mathrm{mm} / \mathrm{min}$ are shown in figures $8 \mathrm{a}, 8 \mathrm{~b}$ and $8 \mathrm{c}$, respectively. It can be observed that the number of dimples and tearing edges of the fractured structure has not decreased in the FSPed composite material when using the above process parameters as shown in Figure $8 \mathrm{a}$ to $8 \mathrm{c}$, which clearly shows that the material is still fairly ductile due to the availability of both narrow and deep dimples. This suggests that there is still no significant decline in the plasticity of the tensile slice. The fracture morphology is composed of deep and small dimples on the fracture surfaces; this suggests that the ductility of the material is still almost the same as that of the monolithic material. The encircled white region suggests that the fracture mechanism is different from ductile fracture. The FSPed samples break large particles into small strong fragments, closing the pre-existing voids and randomizing particles distribution.

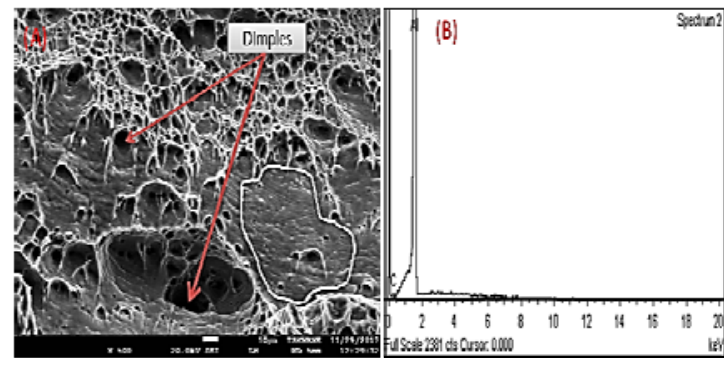

Fig. 7. SEM morphology of fracture surface for pure $\mathrm{Al}$ (a) EDS of pure $\mathrm{Al}$ (b)

In figure 9, it can be observed that the number of dimples and tearing edges of the fractured structure has decreased in the FSPed composite material using the process parameter.

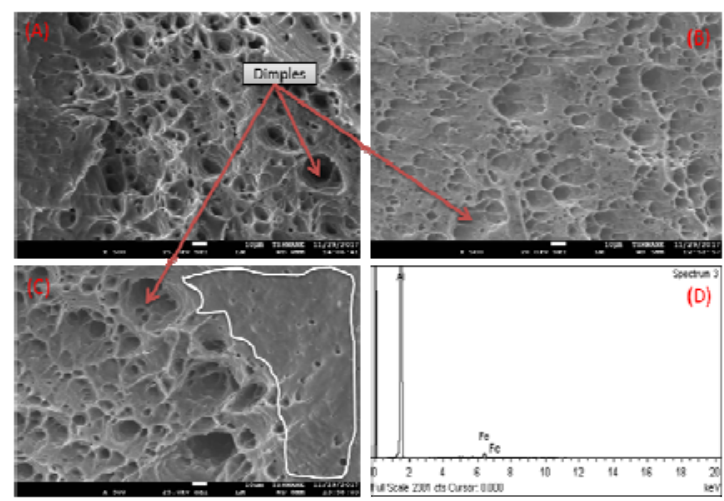

Fig. 8. SEM micrograph of FSPed Al-MMCs, processed at: a) 600 rpm @70mm/min;

b) 600rpm@140mm/min; c) 600rpm@210mm/min; d) EDS of AMC

When compared to the fracture surface of the base metal, a gradual decrease in the number of dimples is observed and this implies that there is a decrease in the plasticity of composite materials, as also observed by Huang et al [13]. The fracture morphology shows a 
perpendicular fracture structure, which supports that the mode of fracture has transited from ductile fracture to brittle fracture. However, an increase in rotational speed results in adequate heat input which is enough to soften the material, allowing reinforcements to be uniformly dispersed into the aluminium matrix.
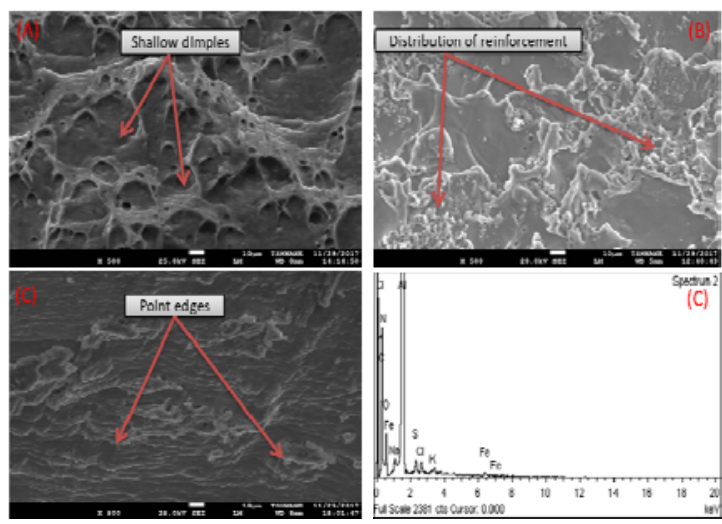

Fig. 9. SEM images for Al-MMCs: a) 800 rpm @ $70 \mathrm{~mm} / \mathrm{min}$; b) $800 \mathrm{rpm}$ @ 140mm/min; c) $800 \mathrm{rpm}$ (a) $210 \mathrm{~mm} / \mathrm{min} ; \mathrm{d})$ EDS of AMC
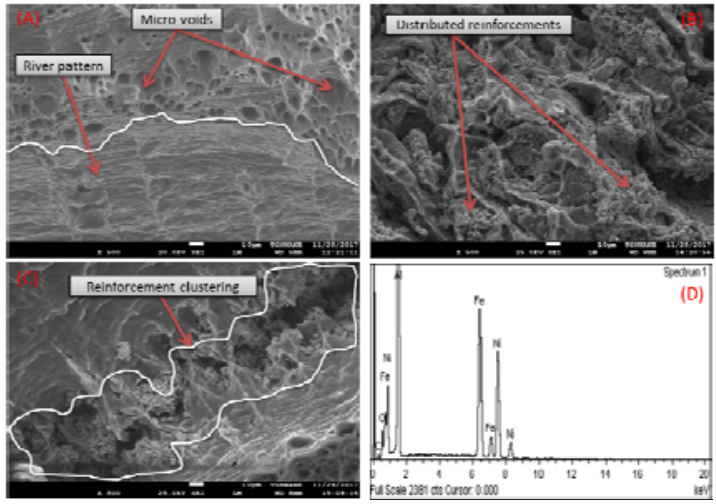

Fig. 10. SEM images for: a) 1000 rpm @70mm/min; b) $1000 \mathrm{rpm} @ 140 \mathrm{~mm} / \mathrm{min}$; c) $1000 \mathrm{rpm}$ @ $210 \mathrm{~mm} / \mathrm{min}$; d) EDS of AMC

The morphology of the fracture surfaces was studied on the FSPed AMC sample produced at a rotational speed of $1000 \mathrm{rpm}$. Figure $10 \mathrm{a}$ and $10 \mathrm{~b}$ show fracture structures that are nearly perpendicular on the tensile direction. However, there are regions of small dimples on the fracture surfaces, as seen in figure 10a. In figure $10 \mathrm{~b}$, bimodal distribution of dimples is observed on the fracture surface of the FSPed AMC sample. Smaller dimples originate from fine grain. It is interesting to note that a large number of reinforcement particles appears at the core of the dimples, suggesting that there is strong interfacial bonding between the Al matrix and $\mathrm{Ni}-\mathrm{Fe}$ particles. High magnification examination of the fracture surface shows areas with $\mathrm{Ni}-\mathrm{Fe}$ reinforcement particles uniformly distributed, as seen in figure 10b, which is further supported by the EDS illustration in figure 10d, which shows the presence of reinforcement bonded to the aluminium matrix. In figure $10 \mathrm{c}$, a cluster of reinforcement particles is observed, with the fracture structures assuming a parallel array to the tensile direction.

\section{CONCLUSIONS}

The study investigated the influence of friction stir process parameters on the tensile property of FSPed fabricated AMCs Al/FE-Ni composites. The process parameters considered in this study are the rotational speed, which ranged between 600 and $1000 \mathrm{rpm}$, and the advancing speed ranging between 70 and 210 $\mathrm{mm} / \mathrm{min}$. For each rotational speed, the advancing speed varied. The tensile strength was found to decrease with the increase of the advancing speed. The best tensile property was achieved at a rotational speed of $1000 \mathrm{rpm}$ and an advancing speed of 70 $\mathrm{mm} / \mathrm{min}$. The high rotational speed was able to cause adequate high heat to be generated during the friction stir processing, which enables severe plastic deformation. The low advancing speed provides the adequate time needed for the proper mixing and uniform dispersion of the reinforcement materials, as well as for the proper diffusion to occur, thereby producing thermodynamically stable reinforcement in the matrix. It is therefore concluded that the processing parameter of $1000 \mathrm{rpm}$ rotational speed and advancing speed of $70 \mathrm{~mm} / \mathrm{min}$ are the optimum process parameters of all the parameters that are considered in this study.

\section{ACKNOWLEDGEMENTS}

The authors would like to thank the Department of Chemical, Metallurgy and Materials science engineering of Tshwane University of Technology for the technical support and provision of research facilities used in this work.

\section{REFERENCES}

[1] Davis J. R., Aluminum and Aluminum Alloys, ASM international: Metal Park, OH, USA, 1993.

[2] Rambabu P., Eswara Prasad N., Kutumbarao V. V., Wanhill R. J. H., Aluminium Alloys for Aerospace Applications, In: Prasad N., Wanhill R. (eds) Aerospace Materials and Material Technologies. Indian Institute of Metals Series, 2017, Springer, Singapore.

[3] Chen Y., Wang H., Wang X., Ding H., Zhao J., Zhang F., Ren Z., Influence of tool pin eccentricity on microstructural evolution and mechanical properties of friction stir processed Al5052 alloy, Materials Science and Engineering: A, 2019, vol. 739, pp. $272-276$

[4] Kumar H., Prasad R., Kumar P., Tewari S.P., Singh J.K., Mechanical and tribological characterization of industrial wastes reinforced aluminum alloy composites fabricated via friction stir processing, Journal of Alloys and Compounds, vol. 831, 2020.

[5] Bharti S., Dutta V., Sharma S., Kumar R., A study on the effect of Friction Stir Processing on the hardness of Aluminium 
6000 series, Materials Today: Proceedings, 2019, vol. 18, iss. 7, pp. 5185-5188.

[6] Chawla N., Chawla K. K., Metal Matrix Composites, Springer, 2006.

[7] Suresh S., Mortensen A., Needleman A., Fundamentals of Metal-Matrix Composites, 1993, Butterworth-Heinemann, Stoneaham.

[8] Storjohann D., Barabash O. M., David S. A., Sklad P. S., Bloom E. E., Babu S.S., Fusion and friction stir welding of aluminum-metal-matrix composites, Metallurgical and Materials Transactions A, 2005, vol. 36, iss. 11, pp. 3237-3247, DOI: $10.1007 / \mathrm{s} 11661-005-0093-4$

[9] Akinlabi E. T., Mahamood R. M., Solid-State Welding: Friction and Friction Stir Welding Processes, Springer, Cham, Switzerland, 2020.

[10] Naik B. B. Reddy K. Y., Reddy G. M., Kumar R. A., Development of high strength and high electrical conductivity $\mathrm{Cu}$ $\mathrm{Cr}-\mathrm{Zr}$ alloy through friction stir processing, Fusion Engineering and Design, vol. 161, 2020.

[11] Mehrian S. S. M., Rahsepar M., Khodabakhshi F., Gerlich A.P., Effects of friction stir processing on the microstructure, mechanical and corrosion behaviors of an aluminum-magnesium alloy, Surface and Coatings Technology, 2020.
[12] Sibisi T. H., Shongwe M. B., Johnson, O. T., Mahamood R. M., Akinlabi S. A., Hassan S., Dong H., Carter K. F., Akinlabi E. T., Effect of processing parameters on corrosion behaviour of Al reinforced with $\mathrm{Ni}-40 \mathrm{Fe}-10 \mathrm{Ti}$ alloy fabricated by FSP, International Journal of Advance Manufacturing Technologies, no. 110, 2020 , pp. 2703-2711, https://doi.org/10.1007/s00170-020-06031-0

[13] Huang G., Wentao Shen Y., Evaluation of the microstructure and mechanical properties of WC particles reinforced Aluminium matrix compositefabricat1ed by friction stir process, Materials characterization, vol. 138, 2018, pp. 26-37.

[14] Sai Sashank J., Sampath P., Sai Krishna R., Sagar Venukumar S. V., Muthukumaran S., Effect of friction stir welding on microstructure and chemical properties of 6063 Aluminium Alloy, Materials Today: Proceedings no. 5, 2018, pp. 8348-8353.

[15] Eskandari H., Taheri R., Khodabakhshi F., Friction-stir processing of an AA8026-TiB2-Al3O2 hybrid nanocomposite Microstructural developments and mechanical properties, Materials science \& engineering, 2016, A660, pp. 84-96.

[16] Akinlabi E. T., Mahamood R. M., Akinlabi S. A. Ogunmuyiwa E., Processing parameters influence on wear resistance behaviour of friction stir processed Al-TiC composites, Advances in Materials Science and Engineering, 2014. 